\title{
Article
}

\section{Design of Porous Carbons for Supercapacitor Applications for Different Organic Solvent-Electrolytes}

\author{
Joshua Bates ${ }^{1}$, Foivos Markoulidis ${ }^{1}\left(\mathbb{D}\right.$, Constantina Lekakou $\left.{ }^{1, *} \mathbb{(}\right)$ and Giuliano M. Laudone ${ }^{2}$ \\ 1 Centre for Engineering Materials, University of Surrey, Guildford GU2 7XH, UK; j.p.bates@surrey.ac.uk (J.B.); \\ f.markoulidis@surrey.ac.uk (F.M.) \\ 2 Faculty of Science and Engineering, University of Plymouth, Plymouth PL4 8AA, UK; \\ G.Laudone@plymouth.ac.uk \\ * Correspondence: c.lekakou@surrey.ac.uk
}

check for updates

Citation: Bates, J.; Markoulidis, F.; Lekakou, C.; Laudone, G.M. Design of Porous Carbons for Supercapacitor Applications for Different Organic Solvent-Electrolytes. C 2021, 7, 15. https://doi.org/10.3390/c7010015

Received: 21 December 2020

Accepted: 26 January 2021

Published: 29 January 2021

Publisher's Note: MDPI stays neutral with regard to jurisdictional claims in published maps and institutional affiliations.

Copyright: (c) 2021 by the authors. Licensee MDPI, Basel, Switzerland. This article is an open access article distributed under the terms and conditions of the Creative Commons Attribution (CC BY) license (https:// creativecommons.org/licenses/by/ $4.0 /)$.

\begin{abstract}
The challenge of optimizing the pore size distribution of porous electrodes for different electrolytes is encountered in supercapacitors, lithium-ion capacitors and hybridized batterysupercapacitor devices. A volume-averaged continuum model of ion transport, taking into account the pore size distribution, is employed for the design of porous electrodes for electrochemical double-layer capacitors (EDLCs) in this study. After validation against experimental data, computer simulations investigate two types of porous electrodes, an activated carbon coating and an activated carbon fabric, and three electrolytes: $1.5 \mathrm{M} \mathrm{TEABF}_{4}$ in acetonitrile (AN), $1.5 \mathrm{M} \mathrm{TEABF}_{4}$ in propylene carbonate $(\mathrm{PC})$, and $1 \mathrm{M} \mathrm{LiPF}_{6}$ in ethylene carbonate:ethyl methyl carbonate (EC:EMC) 1:1 v/v. The design exercise concluded that it is important that the porous electrode has a large specific area in terms of micropores larger than the largest desolvated ion, to achieve high specific capacity, and a good proportion of mesopores larger than the largest solvated ion to ensure fast ion transport and accessibility of the micropores.
\end{abstract}

Keywords: EDLC; activated carbon coating; activated carbon fabric; porous electrodes; electrolyte; ion transport; modeling; computer simulations

\section{Introduction}

Porous carbon is the main electrode material in the majority of symmetric electrochemical double-layer capacitors (EDLCs) [1], due to its good conductivity and ability to be activated into a large specific surface area. It is applied in different formats, including activated carbon fibers and activated carbon fabrics (ACFs) [2,3], activated carbon (AC) powder coatings [4-6], graphene [7-11], graphene oxide [11,12] and carbon nanotubes [13-15], where multiwall carbon nanotubes (MWCNT) also enhance electrode conductivity $[5,16,17]$. Composite electrodes consisting of a blend of these materials combine low resistance with high specific capacitance, resulting in supercapacitors of high power density and high energy density $[5,16-18]$. Such materials are also easy to be recycled [19], where the supercapacitor is disassembled, and a dissolution process is applied to dissolve any electrode binder material $[20,21]$, followed by dielectrophoresis to separate different carbon particulates such as AC, MWCNT and carbon black material [19,22].

EDLC electrodes are designed taking into account three key characteristics: high specific surface area, which defines the capacitance value, fast transport of electrolyte ions to all pores, which defines the power value, and accessibility of all pores to the electrolyte ions, so that the full pore wall surface area accounts for the capacitance. Micropores provide much higher specific area than meso- and macropores. However, a network of meso- and micropores is recommended where the large pores allow for fast ion transport to micropores. It has been observed that very small micropores of similar size as the ion size maximize the electrode capacitance [23]. It can be seen that it is rather difficult to just define empirical rules and measures to take into account the interplay of all three key 
characteristics of EDLC electrodes. A more complex and comprehensive model is needed for the design of meso- and microporous electrodes for EDLCs, which could also be applied to certain battery electrodes relying on similar ion transport and attachment principles, such as lithium-air [24-26] and lithium-sulfur batteries [27,28].

There is a plethora of modeling approaches at different levels. Equivalent circuit models $[2,29]$ are generally used to simulate device behavior [2], to elucidate different effects and degradation with cycling [30], and for power management and control for device and system operation [29]. At the other end, molecular dynamics (MD) simulations are useful in predicting the properties of electrolyte solutions, such as viscosity, diffusion coefficient and conductivity and the size and coordination number of solvated ions [31,32]. Density functional theory (DFT) simulations elucidate interactions [33] and can predict binding energies [34] between ions and pore walls, for example. In general, molecular-level simulations require such large memory and computation time, such that they can model at best a domain of the size of a short micropore. As such, they cannot be applied for the design of the pore architecture of porous electrodes in EDLCs.

Modeling the ion transport employing the Nernst-Planck equation [35] can be carried out through the full pore network, which could be obtained via image analysis of 3D-CT scans [36], for example; however, the problem is that 3D-CT scan and other technologies have a resolution around 1 micron at best, which does not capture the micro- and mesopores and a large portion of macropores of supercapacitor electrodes. The most appropriate model, developed by the authors' group [37], is a volume-averaged continuum model of ion transport through the porous material, taking into account a discretized pore size distribution (PSD) at each numerical point [38]. Pore size distribution of the porous electrode can be obtained from the pressure isotherms in nitrogen adsorption/desorption experiments to low relative pressure, to cover a pore size range of $0.3-120 \mathrm{~nm}$ [38]. This is the model adopted for the design of the porous carbon electrodes in this study.

The model is based on parallel ion transport equations for each pore size in the PSD, including interpore ion flux based on a hierarchical pore line hypothesis [38]. The ions move as solvated ions if the pores can accommodate them [38]. Otherwise, they become desolvated if there is sufficient amount of electrochemical (and thermal energy) to overcome the binding energy between the ion and "bound" solvent molecules [38]. Viscosity, electrolyte conductivity and the diffusion coefficient are continuously updated at each point of the electrode domain during the computer simulation, depending on the changing ion concentration [38-41]. In common with other models by Lekakou's group of species transport through porous media considering multiple pore sizes [42-44], a finite difference/finite volume numerical solution is applied [45].

According to this model, which we shall use as a tool to design porous electrodes, the relationship between ion size (solvated or desolvated, as appropriate) and pore size is a decisive factor in pore accessibility, in the first place, and also in determining the magnitude of the diffusion coefficient and electrolyte conductivity, which affect the rate of transport [38-40]. The size of desolvated ion also plays an important role in the number of ions lining the pore wall under charge voltage in the Stern monolayer [46], which determines the EDLC capacitance. Early in the validation of our model against experimental data, it was realized that using the van der Waals surface wrapping the molecular model of the species to determine the minimum and maximum dimensions, $\mathrm{L}_{\min , \mathrm{VdW}}$ and $\mathrm{L}_{\max , \mathrm{VdW}}$, respectively, and volume of the molecule or ion [28] yielded the best fit between predictions and experimental data. Solvated ion sizes are generally within the upper limit of micropore range [32]; hence, ions can easily migrate through the separator, which has much larger pores in the macropore range of the order of several microns [47] or micron if the separator was fabricated via electrospinning $[48,49]$. For this reason, the model assumes a fully permeable separator of negligible thickness, so that the ion transport is governed by the porous architecture of the anode and cathode [38].

EDLCs with aqueous electrolytes have generally low maximum voltage of operation, $\mathrm{V}_{\max }$, typically below $1.2 \mathrm{~V} \mathrm{[50],} \mathrm{which} \mathrm{is} \mathrm{far} \mathrm{lower} \mathrm{than} \mathrm{that} \mathrm{for} \mathrm{organic} \mathrm{electrolytes}$ 
and ionic liquid electrolytes. Such low-energy devices are not recommended for highvoltage systems, such as automotive and aircraft, or even medium-voltage applications. On the other hand, electronics that operate at low voltage favor solid electrolytes to avoid leaking of liquids. Design of EDLC materials, in this case, depends strongly on the ion diffusion through the solid electrolyte-separator region, which is beyond the scope of this paper. Ionic liquid electrolytes operate to high $\mathrm{V}_{\max }$ to $4.5 \mathrm{~V}$ but are of high viscosity, and their supercapacitors operate at reasonable power only at elevated temperature [51]. Organic electrolytes are the most suitable electrolytes for supercapacitors, operating to about $V_{\max }=3 \mathrm{~V}$ [52]. Popular organic electrolytes for supercapacitors are the low-viscosity solution of $\mathrm{TEABF}_{4}$ in acetonitrile (AN) and the solution of $\mathrm{TEABF}_{4}$ in propylene carbonate (PC) which is of higher viscosity and lower conductivity than AN but less volatile [53]. Recently, there has been increased interest in lithium-ion (Li-ion) electrolytes for lithium-ion capacitors (LICs) [54] and hybridized battery-supercapacitors [55-57], for which porous electrode materials have not yet been optimized.

This study engages with the design of porous electrodes in EDLCs for three representative liquid electrolytes: $\mathrm{TEABF}_{4}$ in $\mathrm{AN}, \mathrm{TEABF}_{4}$ in $\mathrm{PC}$ and $\mathrm{LiPF}_{6}$ in EC-EMC. We pioneer the porous carbon material design by employing computer simulations of the galvanostatic charge-discharge of symmetric EDLC cells based on the advanced volume averaged continuum model developed and presented in [38], which considers the pore size distribution of electrodes. Two typical activated carbon electrodes are simulated with typical PSDs of electrode materials used in supercapacitors. An important feature and contribution of this work is model validation in comparisons of predictions with experimental data.

\section{Materials and Methods}

The following electrode materials were investigated:

(a) ACF fabric ACC-507-15 (Kynol Europa Gmbh, Hamburg, Germany) of a nominal thickness of $0.5 \mathrm{~mm}$ and areal density of $12.05 \mathrm{mg} \mathrm{cm}^{-2}$;

(b) AC coating electrodes consisting of $95 \mathrm{wt} \%$ activated carbon (AC) (Sigma Aldrich: product C9157: 4C Norit A charcoal, peat bog-derived, $\mathrm{BET}_{\mathrm{AC}}=1000 \mathrm{~m}^{2} \mathrm{~g}^{-1}$ ) and $5 \mathrm{wt} \%$ polyvinylidene difluoride $(\mathrm{PVDF})(\mathrm{MW}=534 \times 103$, from Sigma Aldrich, Gillingham, UK).

The electrode ACF fabric and the electrode AC coating were examined using scanning electron microscopy (SEM) on a Jeol 7100 microscope (Zaventem, Belgium) and atomic force microscopy (AFM) in tapping mode on a Bruker Dimension Edge AFM Instrument (Ettlingen, Germany), at the University of Surrey. The electrode ACF fabric and the electrode coating were also characterized in nitrogen adsorption/desorption experiments at $77 \mathrm{~K}$ and relative pressure $\mathrm{P} / \mathrm{P}_{\mathrm{o}}$ in the range of $1 \times 10^{-6}-1$ using a BELSORP-Max (from MICROTRAC, Hope, UK) at the University of Plymouth. Each sample was degassed beforehand at $305 \mathrm{~K}$ for $3 \mathrm{~h}$, at a rate of $9.5 \mathrm{mPa} \mathrm{min}^{-1}$ on average. The pore size distribution was determined from the adsorption/desorption isotherms through GCMC (Grand canonical Monte Carlo) simulations using the BELMaster software at the University of Surrey.

The following symmetric EDLCs are considered in this study, subjected to galvanostatic charge-discharge (GCD) tests at different currents:

Case A: EDLC of $4 \mathrm{~cm}^{2}$ with ACF fabric electrodes of $0.5 \mathrm{~mm}$ thickness and electrolyte $1.5 \mathrm{M} \mathrm{TEABF}_{4} / \mathrm{AN}$;

Case B: EDLC of $2 \mathrm{~cm}^{2}$ with AC coating electrodes of $90 \mu \mathrm{m}$ thickness and areal density of $5.2 \mathrm{mg} \mathrm{cm}^{-2}$, and electrolyte $1.5 \mathrm{M} \mathrm{TEABF}_{4} / \mathrm{AN}$;

Case C: EDLC of $2 \mathrm{~cm}^{2}$ with AC coating electrodes of $100 \mu \mathrm{m}$ thickness and areal density of $5.73 \mathrm{mg} \mathrm{cm}^{-2}$, and electrolyte $1.5 \mathrm{M} \mathrm{TEABF}_{4} / \mathrm{PC}$.

Case D: EDLC of $1.766 \mathrm{~cm}^{2}$ with AC coating electrodes of $90 \mu \mathrm{m}$ thickness and areal density of $4.6 \mathrm{mg} \mathrm{cm}^{-2}$, and electrolyte $1 \mathrm{M} \mathrm{LiPF}_{6}$ in EC:EMC 50:50 $v / v$.

Case E: EDLC of $1.766 \mathrm{~cm}^{2}$ with ACF fabric electrodes of $0.5 \mathrm{~mm}$ thickness and electrolyte $1 \mathrm{M} \mathrm{LiPF}_{6}$ in EC:EMC 50:50 v/v. 
The porous electrode design is based on computer simulations of ion transport [38] during virtual GCD experiments for EDLCs with the two alternative electrode materials and the three electrolyte systems, replicating corresponding experimental studies. The ion transport model [38] used in the simulations is presented in Table A1, Appendix A. The inputted data for the physical properties of the electrolyte solutions are given in Table 1, where $k_{d}$ is the dissociation constant, $\eta_{\mathrm{o}}$ is the solvent viscosity and $\sigma_{2}$ is the solution electrical conductivity.

Table 1. Properties of the electrolyte systems used in this study $[53,58-61]$.

\begin{tabular}{cccc}
\hline Property & $\mathbf{1 . 5} \mathbf{M ~ T E A B F}_{\mathbf{4}} / \mathbf{A N}$ & $\mathbf{1 . 5} \mathbf{M ~ T E A B F}_{\mathbf{4}} / \mathrm{PC}$ & $\mathbf{1 ~ M ~ L i P F}_{\mathbf{6}} / \mathrm{EC}-\mathrm{EMC}$ \\
\hline $\mathrm{k}_{\mathrm{d}}$ & 0.876 & 0.6 & 1 \\
$\eta_{\mathrm{o}}(\mathrm{mPa} \mathrm{s})$ & 0.37 & 1.8 & 1.4 \\
$\sigma_{2}\left(\mathrm{~S} \mathrm{~m}^{-1}\right)$ & 6 & 1.3 & 0.5 \\
\hline
\end{tabular}

\section{Results}

Figure 1 presents SEM and AFM images of the ACF fabric electrode. The SEM image in Figure 1a shows macropores between the crossing yarns of fabric, of the order of 200-500 $\mu \mathrm{m}$ dimensions, with macropores between the fibers in a yarn of the order of 10-20 $\mu \mathrm{m}$ width: these large macropores are considered as the reservoirs of the bulk electrolyte in the electrode, in the model of ion transport. The large-magnification SEM image in Figure $1 \mathrm{~b}$ depicts hierarchical macro- and mesopore architectures of circular crosssection from the surface into the bulk of the fiber ranging from $200 \mathrm{~nm}$ down to $10 \mathrm{~nm}$ (detected on the SEM image). AFM images of a fiber surface, depending on the surface part examined and the fitted maximum depth of the tapping AFM probe, depict mesopores of both cylindrical (Figure 1c) and slit cross-section (Figure 1d) from the fiber surface into the fiber bulk, with the mesopore width ranging from 50 down to $10 \mathrm{~nm}$.
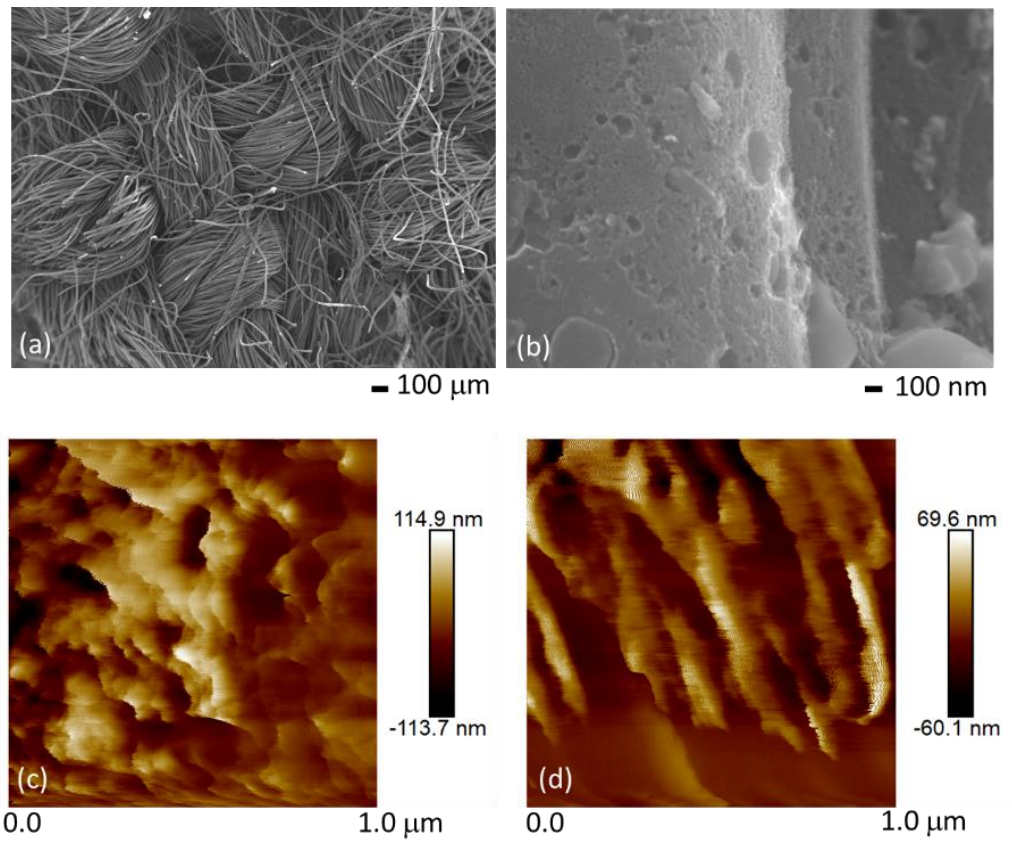

Figure 1. SEM images $(\mathbf{a}, \mathbf{b})$ and AFM images $(\mathbf{c}, \mathbf{d})$ of the surface of the activated carbon fabric (ACF) electrode.

Figure 2 presents SEM and AFM images of the AC coating electrode. The SEM image in Figure 2a presents large macropores of about $10 \mu \mathrm{m}$ between $\mathrm{AC}$ particles, which are considered as the reservoirs of the bulk electrolyte in this type of electrode, in the model of ion transport. Examining the particle surface, macropores of circular cross-section can be 
identified in the SEM images in Figure $2 b-d$, of a diameter from $500 \mathrm{~nm}$ down to $20 \mathrm{~nm}$ (detected). Such features are also detected in the AFM images (Figure 2e-h), where slit type of pore channels can also be identified in Figure $2 \mathrm{~g}$, of the order of $10 \mathrm{~nm}$ width.
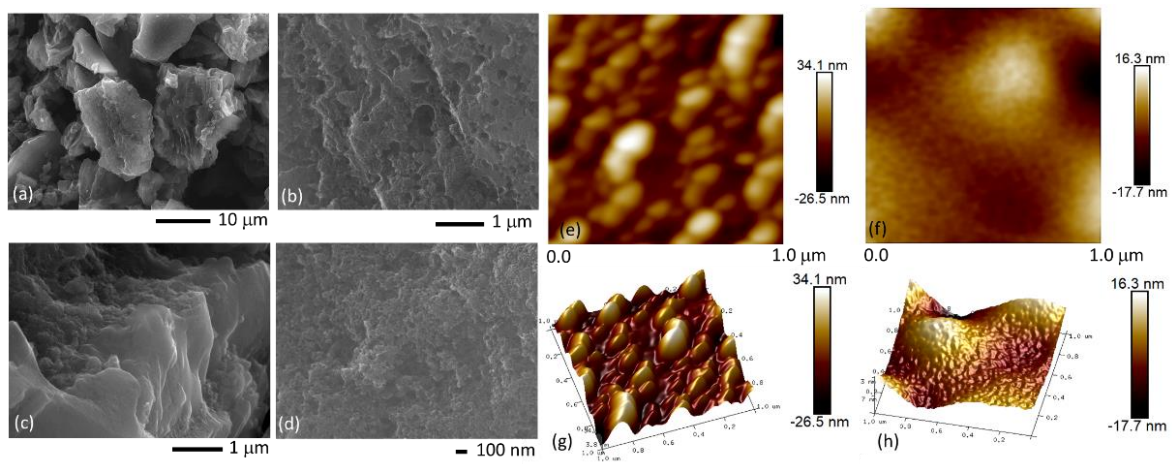

Figure 2. SEM images (a-d) and AFM images (e-h) of the surface of the AC coating electrode.

Nitrogen adsorption/desorption experiments for the ACF fabric yielded a type I isotherm (Figure 3a), indicating a generally microporous material. Using the t-plot method in the BELMaster software, the specific surface area of the ACF fabric was calculated as $\mathrm{BET}_{\mathrm{ACF}}=1734.3 \mathrm{~m}^{2} \mathrm{~g}^{-1}$. Employing the assumption of slit pore shape, which is considered to be the case for micropores of carbonaceous materials, the GCMC method was applied to derive the PSD of ACF fabric from the experimental data of the adsorption isotherm, and the results are presented in Figure $3 \mathrm{~b}$. The incremental PSD curve is generally bimodal with small peaks at 0.38 and $0.57 \mathrm{~nm}$ and main peaks at 0.64 and $1.31 \mathrm{~nm}$. Furthermore, a discrete PSD of 12 pore sizes was fitted to the GCMC curve and is also presented in Figure $3 \mathrm{~b}$. The discrete PSD will be used as input data of the different pore sizes in the simulations for the ACF electrodes in this paper.
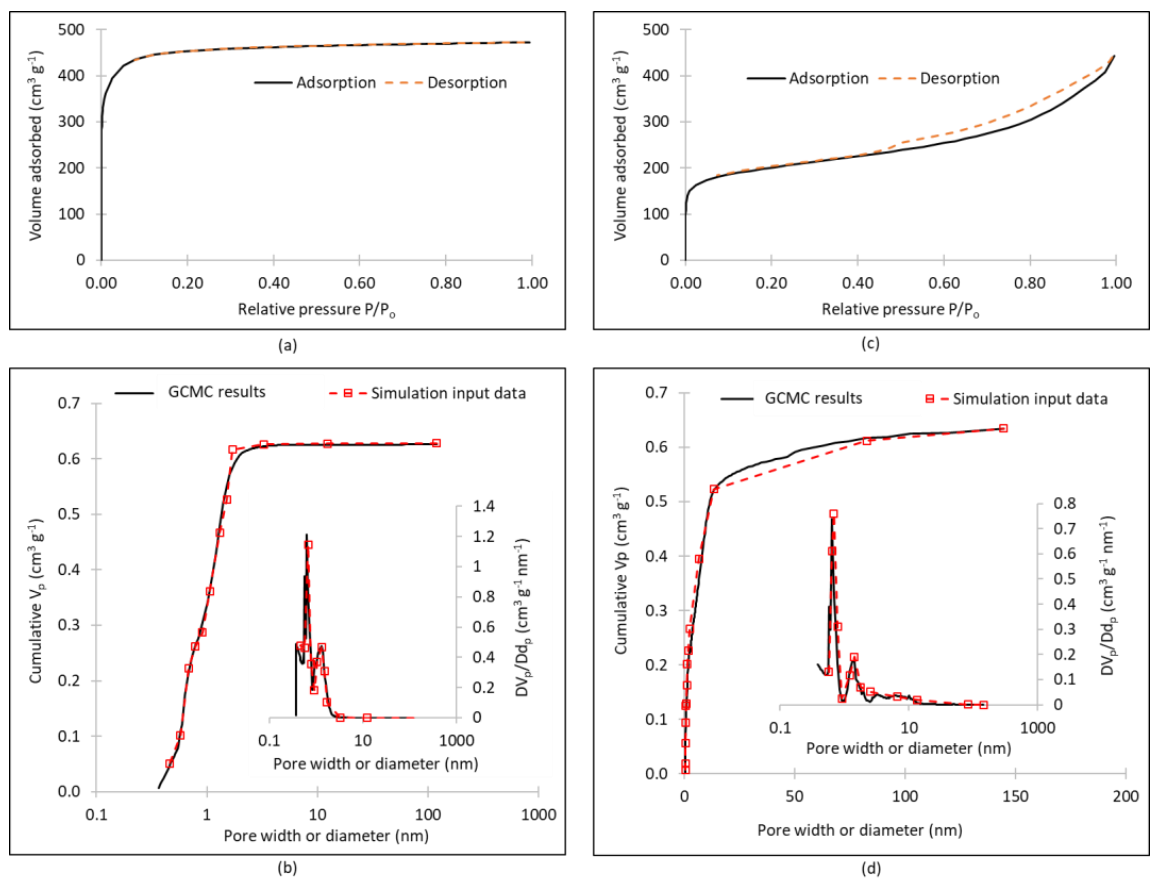

Figure 3. Nitrogen adsorption/desorption experimental data and analysis results: adsorption/desorption isotherms for (a) the ACF fabric and (c) the AC coating; pore size distribution (PSD), derived from the experimental adsorption isotherms using the GCMC method, of (b) the ACF fabric and (d) the AC coating from experimental data and fitted discrete PSD lines used as input data in the simulations in this paper. 
Nitrogen adsorption/desorption experiments for the AC coating yielded a type III isotherm (Figure 3c), indicating a hierarchical pore structure with accessible micropores. The GCMC method was also applied to derive the PSD of the AC coating from the experimental data of the adsorption isotherm, and the results are presented in Figure $3 \mathrm{~d}$. The incremental PSD curve is generally bimodal with a small peak at $0.39 \mathrm{~nm}$, main peaks at 0.68 and $1.41 \mathrm{mn}$, and further small peaks at 1.77, 3.19 and $9.93 \mathrm{~nm}$. A discrete PSD line of 14 pore sizes was fitted to the experimental PSD curve and is also presented in Figure 3d. The discrete PSD will be used as input data of the different pore sizes in the simulations for the AC coating electrodes in this paper.

Table 2 presents the ion parameters for different electrolyte solutions, as discovered in the literature. It seems that both $\mathrm{ACF}$ fabric and $\mathrm{AC}$ coating have their major peak in their PSD in Figure 3, at 0.64 and $0.68 \mathrm{~nm}$ respectively, at the appropriate pore size to accommodate the $\mathrm{TEA}^{+}$desolvated ion in the $\mathrm{TEABF}_{4}$ electrolytes and, thus, maximize specific capacitance. ACF also has also a smaller peak at $0.57 \mathrm{~nm}$ that can just accommodate the $\mathrm{Li}^{+}$desolvated ion in the Li-ion electrolyte.

Table 2. Values of parameters of the electrolyte systems used in this study $[31,38,62,63]$.

\begin{tabular}{cccc}
\hline Electrolyte Ion & $\mathbf{L}_{\mathbf{m i n}, \mathbf{V d W}}(\mathbf{n m})^{\mathbf{1}}$ & $\mathbf{n}_{\mathbf{c}}{ }^{\mathbf{2}}$ & $\mathbf{E}_{\text {ion/solvent }} \mathbf{( k J ~ m o l}^{\mathbf{- 1}} \mathbf{~}^{\mathbf{3}}$ \\
\hline $\mathrm{TEA}^{+}$ & 0.60 & $6(\mathrm{AN}), 3(\mathrm{PC})$ & \\
$\mathrm{BF}_{4}{ }^{-}$ & 0.45 & $3.3(\mathrm{AN}), 3(\mathrm{PC})$ & -222 \\
$\mathrm{TEA}^{+} / \mathrm{AN}$ & 1.1 & 15.5 & -196 \\
$\mathrm{BF}_{4}^{-} / \mathrm{AN}$ & 0.85 & 6.75 & -10 \\
$\mathrm{TEA}^{+} / \mathrm{PC}$ & 1.28 & 13 & -35 \\
$\mathrm{BF}_{4}^{-} / \mathrm{PC}$ & 1.04 & 6 & \\
$\mathrm{Li}^{+}$ & 0.56 & 4 & -400 \\
$\mathrm{PF}_{6}-$ & 0.5 & 0 & -70 \\
$\mathrm{Li}^{+} / \mathrm{EC}-\mathrm{EMC}$ & 1.8 & 4 & \\
$\mathrm{PF}_{6}-/ \mathrm{EC}-\mathrm{EMC}$ & 1.4 & 3 & \\
\hline
\end{tabular}

${ }^{1}$ Minimum ion size (desolvated or solvated) from the Van der Waals volume. ${ }^{2}$ Coordination number. ${ }^{3}$ Binding energy between ion and solvent from the coordination solvent shell.

The first step was to conduct a sensitivity analysis of the proposed model, in a GCD simulation at $2.5 \mathrm{~mA} \mathrm{~cm}^{-2}$ for the examples of Cases A, B, and C. The graph in Figure 4 contains the experimental data, the predictions with the electrolyte data of Table 2 used in the simulations (Figure 4-predictions standard), a simulation with size of solvated ions as the center-of-mass radial distribution function (RDF) predicted directly from MD simulations by Feng for AN solvent [31] and $\mathrm{Hu}$ for PC solvent [63], and parametric studies of changing the desolvation energy by $+50 \%,-50 \%$, and $E_{\text {ion }} /$ solvent $=0$. The model and algorithm are very sensitive to large solvated ions for electrode materials with the largest pore size peak smaller than the solvated ion as in Case A: ACF fabric, $\mathrm{d}_{\mathrm{p} \text {,peak }}=1.31 \mathrm{~nm}$ in Figure $3 \mathrm{~b}$ against $\mathrm{d}_{\mathrm{TEA}+/ \mathrm{AN}}=1.55 \mathrm{~nm}$ from MD simulations. Hence, the solvated ion dimensions determined from a simple Van der Waals volume method in Table 2 yield better predictions, closer to the experimental data in Figure 4 for Case A than the solvated ion size from MD simulations and, hence, are used as input data in the simulations henceforth Changes in the desolvation energy by $\pm 50 \%$ bring relatively small changes in the total GCD cycle, of the order of $5 \%$ on average. Setting $E_{\text {ion/solvent }}=0$ brings much greater changes in the total GCD cycle, in the range of $20-35 \%$ (36\% in Case A, $16 \%$ in Case B and $23 \%$ in Case C) compared to the predictions from a standard simulation. 


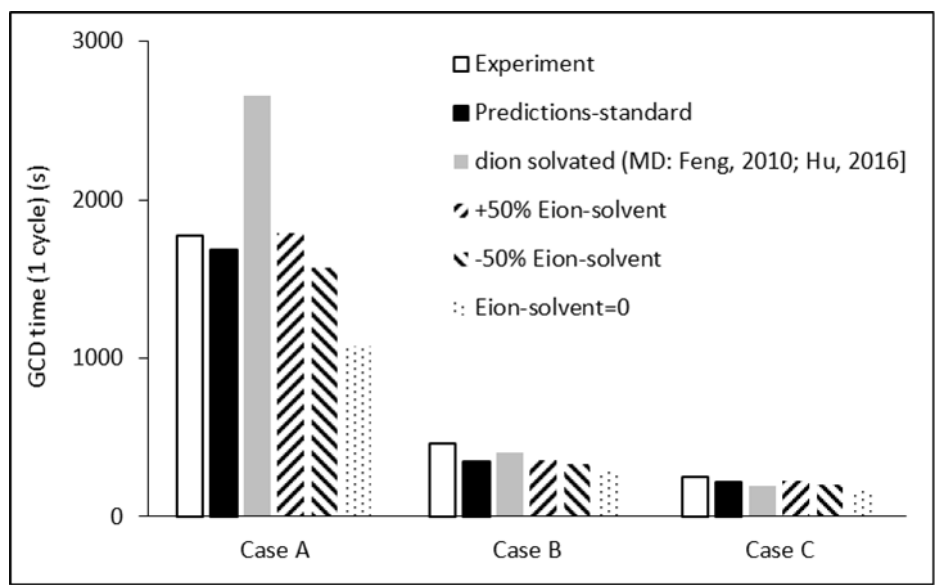

Figure 4. Results of a sensitivity analysis, for a galvanostatic charge-discharge (GCD) cycle time at a GCD current density of $2.5 \mathrm{~mA} \mathrm{~cm} \mathrm{c}^{-2}$ of cell area.

Figure 5a presents the predicted charge-discharge curves for Case Study A at four different current densities: $2.5,5,25$ and $50 \mathrm{~mA} \mathrm{~cm}{ }^{-2}$ and the experimental data for the corresponding case study from [18,62]. Generally, good agreement can be seen between predictions and experimental data. At the high current of $50 \mathrm{~mA} \mathrm{~cm}^{-2}$, at the beginning of discharge, the voltage drop due to commonly known reasons of equivalent-in-series resistance and ion diffusion in equivalent electric circuit models [2] seems to follow a parallel trend to that of the experimental line. The prediction curves at all currents seem to have a small change in slope around $0.8-1.1 \mathrm{~V}$, especially visible at the low currents, reminiscent of small intercalation bumps in pseudocapacitors [64].

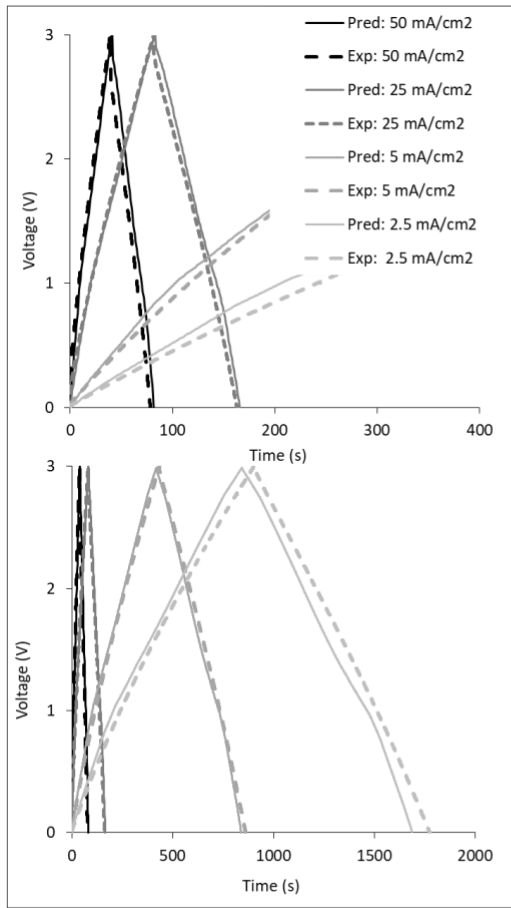

(a)

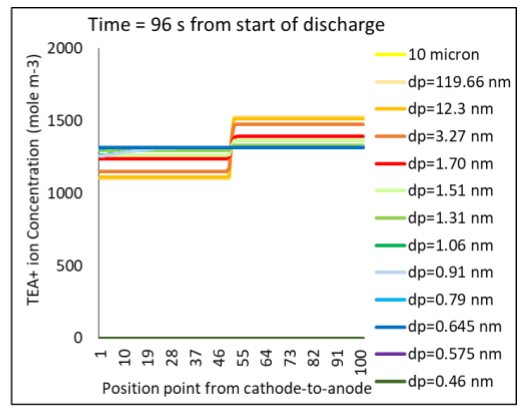

(b)

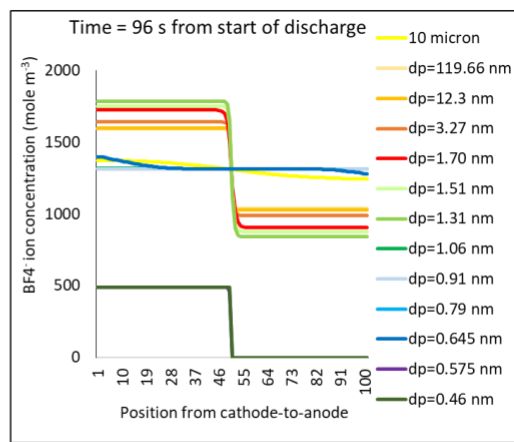

(c)

Figure 5. (a) Predicted GCD curves for Case A ( $4 \mathrm{~cm}^{2}$ electrochemical double-layer capacitor (EDLC) cell, with ACF electrodes and 1.5 $\mathrm{M} \mathrm{TEABF}_{4} / \mathrm{AN}$ electrolyte) and experimental data [18,62]. (b,c) Ion concentration profiles across the EDLC cell thickness $95 \mathrm{~s}$ after the start of discharge in GCD cycle at $2.5 \mathrm{~mA} \mathrm{~cm}^{-2}$ for Case A: cell thickness in Case A is $1 \mathrm{~mm}$ consisting of $0.5 \mathrm{~mm}$ cathode and $0.5 \mathrm{~mm}$ anode (separator is considered fully permeable by ions and of negligible thickness). 
Figure $5 \mathrm{~b}, \mathrm{c}$ displays the predicted $\mathrm{TEA}^{+}$and $\mathrm{BF}_{4}{ }^{-}$ion concentration profiles across the EDLC cell, from the cathode to the anode, $96 \mathrm{~s}$ after the start of discharge in a GCD cycle at the low current of $2.5 \mathrm{~mA} \mathrm{~cm}^{-2}$ for Case A. Apart from the change, either side of the separator in the middle of the cell, the ion concentration profiles are generally flat in the main cathode and main anode region, all the way to the border with the corresponding current collector. At $11 \%$ time of the full discharge, there is still most charge stored in the respective electrodes: as expected, there is still a deficiency of $\mathrm{TEA}^{+}$ions in the cathode and an excess of $\mathrm{TEA}^{+}$ions in the anode, and the opposite happens with the $\mathrm{BF}_{4}{ }^{-}$ions.

Figure 6 presents the ion concentration profiles at $x=0$ (cathode/current collector) and $\mathrm{x}=\mathrm{L}$ (anode/current collector) against time for Case A. The ion transport across the electrodes is fully captured: during charge, the $\mathrm{TEA}^{+}$ion concentration decreases in the cathode and increases in the anode, whereas the $\mathrm{BF}_{4}{ }^{-}$ion concentration increases in the anode and decreases in the cathode; the reverse happens during discharge. Solvated $\mathrm{TEA}^{+}$ion transport takes place in macro-, meso- and micropores down to $1.31 \mathrm{~nm}$ pore size, and desolvated TEA ${ }^{+}$ions are transported in pores of 1.06 and $0.91 \mathrm{~nm}$ size. The TEA ${ }^{+}$ion concentration in the pores of $0.79 \mathrm{~nm}$ and $0.645 \mathrm{~nm}$ remains constant, as the initial electrolyte concentration, indicating no noticeable ion transport in these pores, which is attributed to the low ion diffusivity due to high pore constrictivity for these small micropores. $\mathrm{BF}_{4}{ }^{-}$ion concentration changes in all pore sizes in the cathode, indicating ion transport in all pores in desolvated state for pores smaller than $0.85 \mathrm{~nm}$. While the $0.58 \mathrm{~nm}$ and $0.46 \mathrm{~nm}$ pores did not contain any electrolyte initially, as these pores cannot accommodate the TEA ${ }^{+}$ ions (even desolvated), desolvated $\mathrm{BF}_{4}{ }^{-}$ions are still transported in the cathode and their concentration rises to a maximum of 209 mole $^{-3}$ at the end of charge. In the anode, a restriction was placed to the motion of $\mathrm{BF}_{4}{ }^{-}$ions in the model and computer algorithm for pores smaller than $d_{\text {TEA+ }}=0.67 \mathrm{~nm}$, following the findings in in situ NMR studies of cation adsorption only in the anode [65]. In addition, the predictions in Figure 6 go beyond this restriction, as they demonstrate that there is no $\mathrm{BF}_{4}{ }^{-}$ion transport in the cathode for $\mathrm{d}_{\mathrm{p}} \leq 0.91 \mathrm{~nm}$ (constant $\mathrm{BF}_{4}{ }^{-}$concentration equal to the initial concentration in those pores), which is attributed to pore constrictivity reducing the diffusion coefficient and high ion concentration effects in these small pore sizes in the anode. These predictions capture the findings of Forse et al. [65] without the need for the additional externally imposed restriction in the algorithm. On the other hand, ion exchange occurs for the bigger micro- and also the meso- and macropores in the anode, also agreeing with the findings of the NMR study by Deschamps et al. [66]. Examining the small bumps in the predicted voltage profile in Figure $5 \mathrm{a}$ in relation to the ion concentration profiles in different pore sizes in Figure 6, the following observations have been made: (i) the small bump at $1.1 \mathrm{~V}$ (209 s) during charge is attributed to the desolvation of $\mathrm{TEA}^{+}$and its start of migration and diffusion into the smallest anode pore, $d_{p}=0.91 \mathrm{~nm}$, when it enters the simulation results during charge; (ii) the small bump at $0.9 \mathrm{~V}$ (1490 s) during discharge is attributed to the desolvation of $\mathrm{BF}_{4}{ }^{-}$and its start of migration and diffusion into the smallest anode pore, $d_{p}=0.645 \mathrm{~nm}$, when it returns during discharge. 


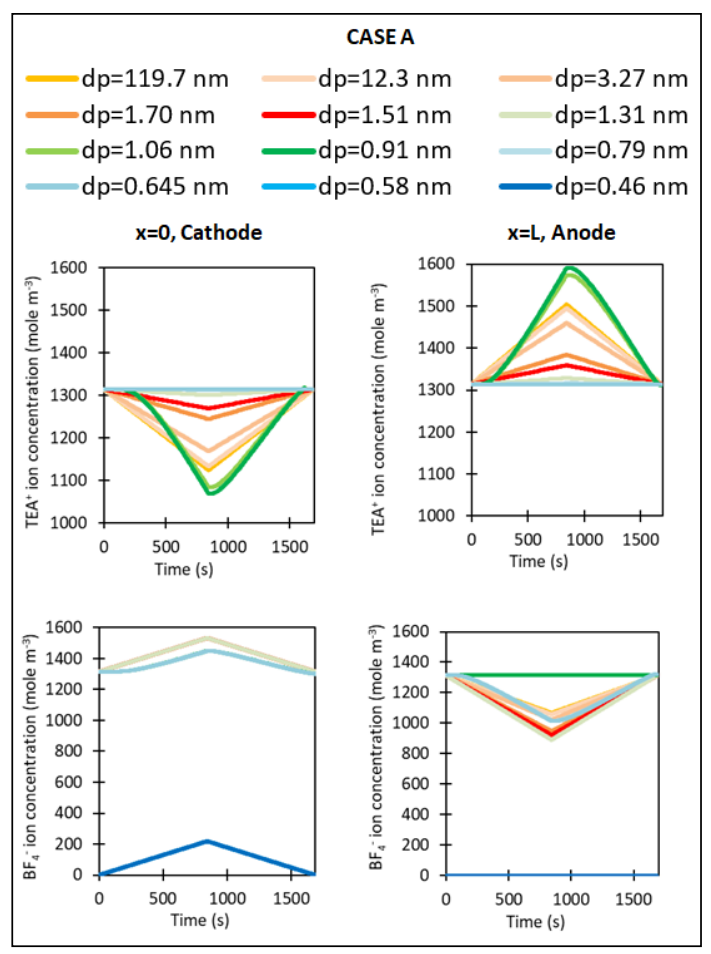

Figure 6. Predicted ion concentration profiles against time at $\mathrm{x}=0$ (cathode/current collector) and $\mathrm{x}=\mathrm{L}$ (anode/current collector) for Case A: ACF fabric electrodes and 1.5 M TEABF $/ \mathrm{AN}$ electrolyte.

Similar trends are observed in the ion concentration profiles versus time for Case $\mathrm{B}$ in Figure 7, The difference is that, due to the larger proportion of larger micropores and mesopores in the AC coating electrodes in Case B according to the PSD in Figure 3d compared to the ACF electrodes in Case A (PSD in Figure $3 b$ ), these larger pores facilitate ion transport in Case $\mathrm{B}$, which results in a higher maximum concentration of $\mathrm{TEA}^{+}$ions in the smallest micropore $0.91 \mathrm{~nm}$ in size, into which they are transported, than in Case A for the same size micropore. In both cases, ion desolvation took place before the TEA ${ }^{+}$ ions enter the $0.91 \mathrm{~nm}$ micropore. The ion concentration profiles against time for Case $\mathrm{C}$ in Figure 7 display smaller rise or decrease in ion concentration at the end of charge than in Case B, where both cases have the same AC coating electrodes but different electrolyte solvent, with PC in Case C being a larger molecule than AN in Case B, resulting in reduced ion transport rate because of lower diffusivity due to pore constrictivity against the larger PC-solvated ions. The smaller pore size accessible by desolvated TEA ${ }^{+}$ions is $1.2 \mathrm{~nm}$, whereas desolvated $\mathrm{BF}_{4}{ }^{-}$ions reach the smallest pores of $0.49 \mathrm{~nm}$ in the cathode. In the anode, there is no transport of $\mathrm{BF}_{4}{ }^{-}$ions for pores smaller than $1.2 \mathrm{~nm}$, agreeing with the findings of Forse et al. [65] in their in situ NMR studies.

Case studies D and E involve electrolyte $1 \mathrm{M} \mathrm{LiPF}_{6}$ in EC:EMC 50:50 v/v with the predicted ion concentration profiles against time presented in Figure 8. Linear profiles of the $\mathrm{Li}^{+}$concentration are depicted for both types of electrodes, AC coating (Case D) and ACF fabric (Case E), due to the small size of desolvated $\mathrm{Li}^{+}$, which allows for easier transport through small micropores than $\mathrm{TEA}^{+}$in the previous organic electrolyte systems. An ion exchange mechanism is followed in both case studies. 


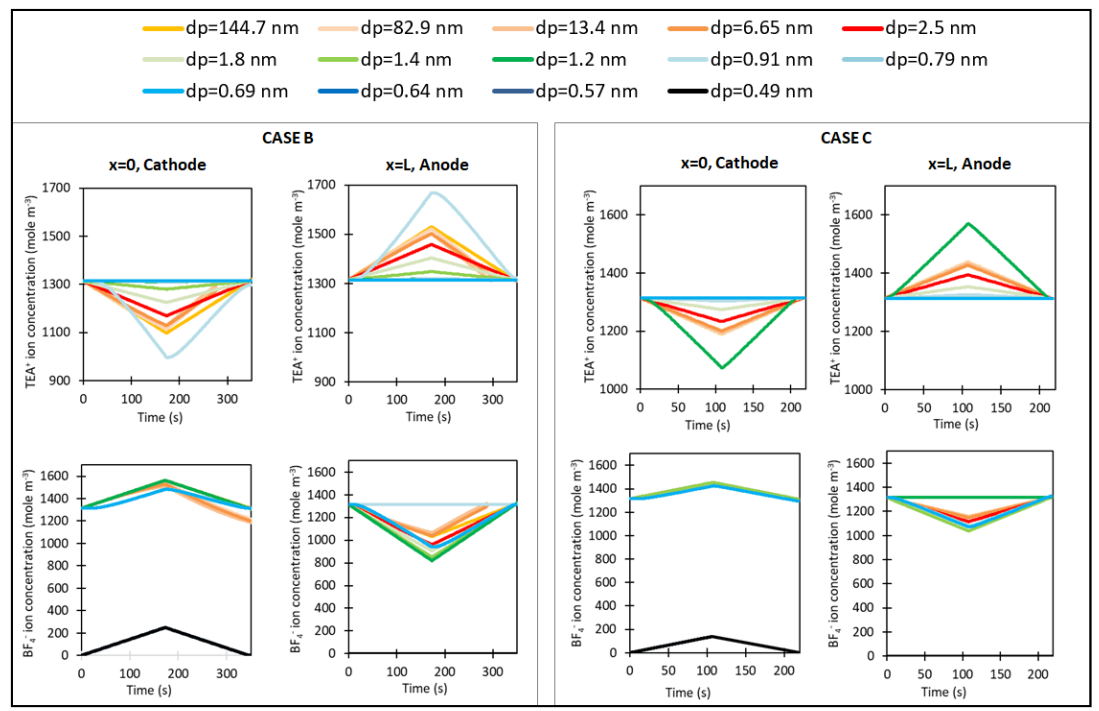

Figure 7. Predicted ion concentration profiles against time at $x=0$ (cathode/current collector) and $x$ $=\mathrm{L}$ (anode/current collector) for AC coating electrodes and Case B: $1.5 \mathrm{M} \mathrm{TEABF}_{4} / \mathrm{AN}_{\text {electrolyte }}$ and Case C: $1.5 \mathrm{M} \mathrm{TEABF}_{4} / \mathrm{PC}$ electrolyte.
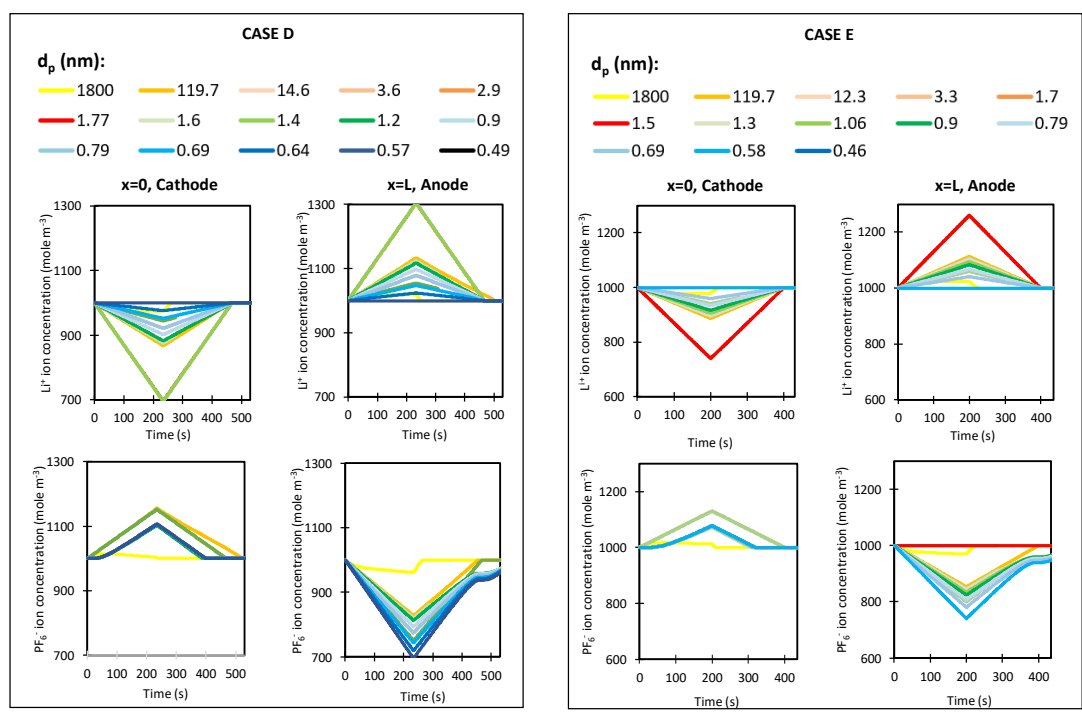

Figure 8. Predicted ion concentration profiles against time at $\mathrm{x}=0$ (cathode/current collector) and $\mathrm{x}=\mathrm{L}$ (anode/current collector) for EDLC with electrolyte $1 \mathrm{M} \mathrm{LiPF}_{6} / \mathrm{EC}-\mathrm{EMC}$ and: Case D: AC coating electrodes and Case E: ACF fabric electrodes.

The maximum change in $\mathrm{Li}^{+}$concentration in Figure 8 occurs in $1.4 \mathrm{~nm}, 1.6 \mathrm{~nm}$ and $1.77 \mathrm{~nm}$ pores for Case $\mathrm{D}$, and $1.5 \mathrm{~nm}$ and $1.7 \mathrm{~nm}$ for Case E, where all these pores contain deformed solvated $\mathrm{Li}^{+}$ions. In discharge, $\mathrm{Li}^{+}$concentration decreases also linearly to the original $1 \mathrm{M}$ concentration for most pore sizes, apart from the $119 \mathrm{~nm}$ macropore, which empties to $1 \mathrm{M}$ after some delay. The maximum rise in the $\mathrm{PF}_{6}{ }^{-}$concentration profiles in the cathode occurs in $2.9 \mathrm{~nm}, 3.6 \mathrm{~nm}, 14.6 \mathrm{~nm}$ and $119 \mathrm{~nm}$ pores for Case $\mathrm{D}$, and 3.3, 12.3 and $119 \mathrm{~nm}$ for Case E, in which the solvated anion can move easily (see Table 2). The slower transport of $\mathrm{PF}_{6}{ }^{-}$in pores smaller than $1.8 \mathrm{~nm}$ corresponds to the limit of the tetrahedral solvated $\mathrm{Li}^{+}$ion [38], and seems to be linked to the ion exchange mechanism, where a lag is encountered for the $\mathrm{PF}_{6}{ }^{-}$concentration to rise at the start of charge. In the anode, the delay of the $\mathrm{PF}_{6}{ }^{-}$to return to $1 \mathrm{M}$ in pores smaller than $1.2 \mathrm{~nm}$ at the end of discharge is due to the fact of insufficient electrochemical energy to overcome the desolvation energy barrier towards the end of discharge for $\mathrm{PF}_{6}{ }^{-}$to desolvate and 
return to the small pores. This creates a chain effect in delaying to empty the cathode macropore of $119 \mathrm{~nm}$ from $\mathrm{PF}_{6}{ }^{-}$ions, as well as delaying emptying the anode macropore of $119 \mathrm{~nm}$ of $\mathrm{Li}^{+}$ions.

Figure 9a presents the predicted GCD time duration of the tested EDLCs at different current densities, normalized by the mass of the two electrodes of the EDLC to cater for differences in the electrode areal density and size of cells. Experimental data were available $[16,18,38,62]$ for Cases A, B, C and D and are used to compare with predictions and validate the numerical model. In all cases, the experimental specific GCD cycle (per gram of electrodes) is $5-10 \%$ longer than the predictions at the lowest tested current density, related to possibly a little slower desolvated ion generation and diffusion in the predictions than in the experiment, which apart from the value of binding energy might also be due to the limited number of points in the discretized pore size distribution inputted in the simulations. On the other hand, the predicted specific GCD cycle is a little longer than the experimental data at high current density.
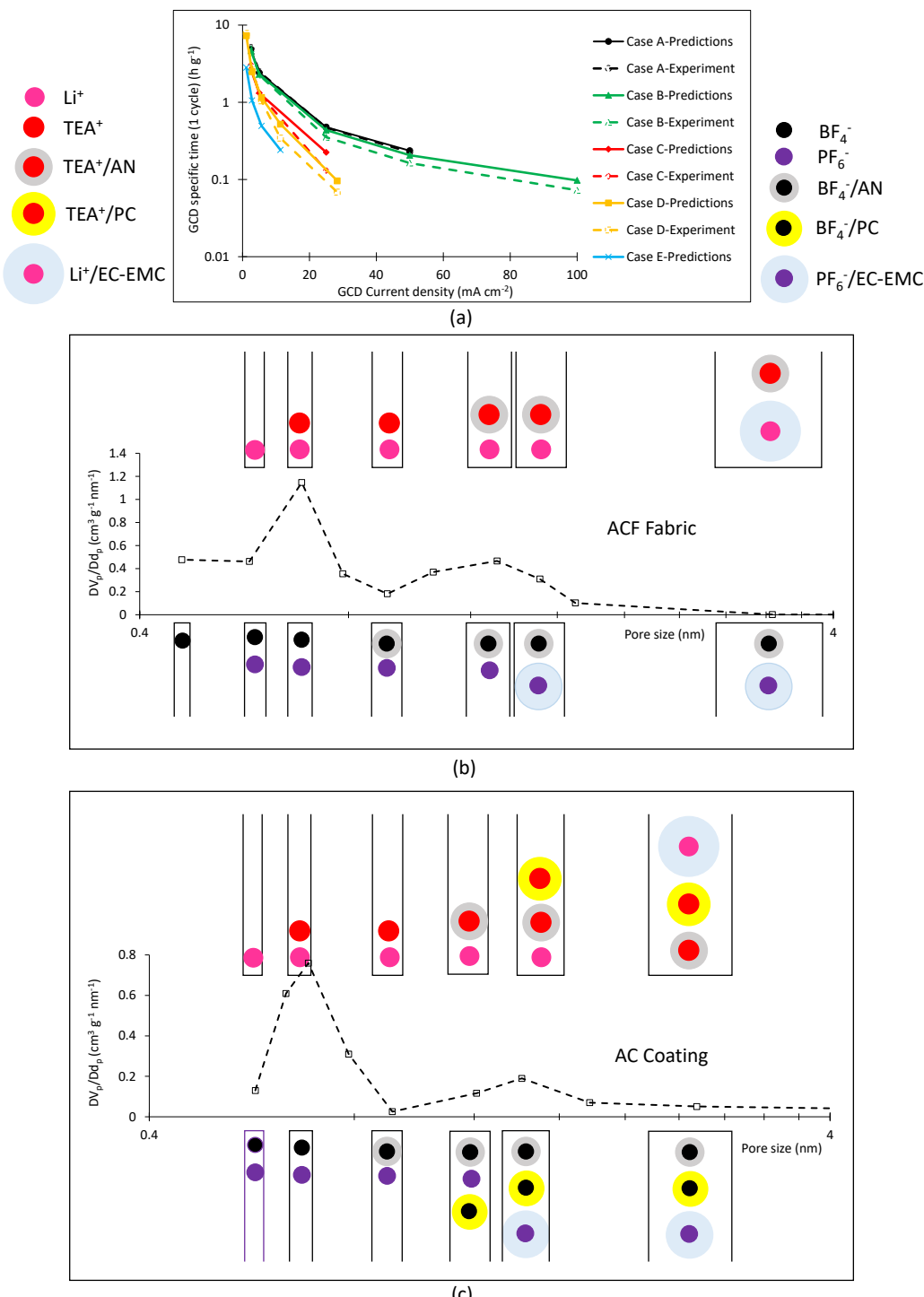

Figure 9. Predicted EDLC performance in (a), and relationship between the size of ion (solvated or desolvated) and pore size in (b) for ACF fabric and (c) for AC coating. Electrodes: ACF fabric in Cases A and E; AC coating in Cases B, C and D. Electrolyte: $1.5 \mathrm{M} \mathrm{TEABF}_{4} / \mathrm{AN}$ in Cases A and B; $1.5 \mathrm{M} \mathrm{TEABF}_{4} / \mathrm{PC}$ in Case C; $1 \mathrm{M} \mathrm{LiPF}_{6} / \mathrm{EC}-\mathrm{EMC}$ in Cases D and E. Experimental data in (a) from studies $[16,18,38,62]$. 


\section{Discussion}

The predicted differences between the performance of the different Cases presented in Figure $9 a$ are fully reflected in the experimental data. Figure $9 b, c$ illustrate the relationship between ion size (solvated or desolvated) and pore size from the discretized PSD lines inputted in the computer simulations, for ACF fabric and AC coating, respectively, to aid explaining these differences in performance. It must be noted that pores smaller than the desolvated ion size are not in use during the operation of EDLC. The importance of the relation between solvated or desolvated ion size and pore size of supercapacitor electrodes, as well as the ease of ion desolvation for different solvents, has been recognized in the past ([67], for example). The advantage of the present design study is the use of a comprehensive ion transport model, incorporating the pore size distribution, the ion transport in the form of solvated or desolvated ion and the use of binding energy to control ion desolvation when compared to the available electrochemical (and thermal) energy. As a result, the findings in this study are quantitative with predicted GCD cycle.

Case D exhibits the longest specific GCD cycle at the lowest tested current density, which is related to the best specific capacitance, which is attributed to (a) the smallest size of the desolvated cation $\left(\mathrm{Li}^{+}\right.$compared to $\left.\mathrm{TEA}^{+}\right)$that allows a high concentration of $\mathrm{Li}^{+}$ions to line the pore walls in the Stern monolayer and (b) the good accessibility of the AC coating micropores due to the good portion of meso- and large micropores in the AC coating allowing transport of the large solvated ion $\mathrm{Li}^{+} /$EC-EMC (Figure 9c). On the other hand, Case E with ACF fabric electrodes and the same electrolyte has about $1 / 3$ of the specific GCD time of Case D because of poor accessibility of its large micropore surface area by the cations, which is due to the fact that ACF fabric (Figure $9 b$ ) has $1 / 30$ of the specific pore volume of $\mathrm{AC}$ coating of meso- and large micropores, allowing transport of the large solvated ion $\mathrm{Li}^{+}$/EC-EMC. Increasing the current density shortens the specific GCD cycle of Cases D and E much faster than in Cases A, B and C. This is attributed to the size of solvated ion $\mathrm{Li}^{+}$/EC-EMC, which is much larger than that of the other two solvated cations of the other electrolytes, $\mathrm{TEA}^{+} / \mathrm{AN}$ and $\mathrm{TEA}^{+} / \mathrm{PC}$, slowing down solvated ion transport in meso- and large micropores, which governs the EDLC performance at medium and high current densities. In fact, the large solvated cation effect against the available mesoand large micropore specific volume reduces the limit of maximum current density in the operation of Cases D and E, but also in Case $C$ which has the next largest solvated cation $\mathrm{TEA}^{+} / \mathrm{PC}$.

Case $\mathrm{B}, \mathrm{AC}$ coating electrodes with $1.5 \mathrm{M} \mathrm{TEABF}_{4} / \mathrm{AN}$ electrolyte, has the most balanced overall performance features for an EDLC, with a good specific capacitance across a large range of current densities, which is attributed to the reasonable specific surface area of the AC coating and good accessibility of micropores by cations, due to the good transport of the smallest solvated cation $\mathrm{TEA}^{+} / \mathrm{AN}$ amongst all investigated electrolytes, and the good proportion of meso- and large micropores in the AC coating being able to accommodate the motion of the solvated ions. In all discussions, the focus has been on the size of the cation, as the solvated anions are all smaller than their associated solvated cations, and the desolvated anions are smaller than or of similar size as the desolvated cations.

\section{Conclusions}

The study has demonstrated the usefulness of the volume-averaged continuum model of ion transport through porous electrodes in supercapacitors, taking into account the pore size distribution. Such a model allows confidence in the design of the porous electrodes in terms of optimizing their pore size distribution for a certain or a specified range of electrolytes. An AC coating with a very good specific surface area, for high specific capacitance, and a good proportion of mesopores, for solvated ion transport and accessibility of micropores, may be designed to be suitable for a range of medium maximum voltage electrolytes, from the best EDLC electrolyte $\mathrm{TEABF}_{4} / \mathrm{AN}$ to the lower-volatility electrolyte $\mathrm{TEABF}_{4} / \mathrm{PC}$, to Li-ion electrolytes used in LICs and hybridized battery-supercapacitor devices. Although EDLCs with Li-ion electrolytes might not reach the highest current 
densities of EDLCs with electrolyte $\mathrm{TEABF}_{4} / \mathrm{AN}$, their maximum current density, at $10 \mathrm{C}$ of the battery, for example, in a hybridized battery-supercapacitor device, is still a low current density for an EDLC. Furthermore, Li-ion electrolytes bring the highest specific capacitance at a very low current density, equivalent to $0.1 \mathrm{C}$ or $1 \mathrm{C}$ of the battery part in a hybridized battery-supercapacitor device.

Author Contributions: Conceptualization, C.L.; methodology, J.B., F.M., C.L. and G.M.L.; software, J.B. and C.L.; validation, J.B. and C.L.; formal analysis, J.B., F.M., C.L. and G.M.L.; investigation, J.B. (experiment, simulations), F.M. (molecular modeling of $\mathrm{TEABF}_{4}$ electrolyte ions), C.L. (simulations) and G.M.L. (experiment: $\mathrm{N}_{2}$ adsorption/desorption experiments); resources, C.L.; data curation, C.L.; writing-C.L. and J.B.; supervision, C.L.; funding acquisition, C.L. All authors have read and agreed to the published version of the manuscript.

Funding: This research was partially funded by EPSRC under the HiPoBat project: ISCF Wave 1: High Power Material Hybridized Battery, EP/R022852/1.

Institutional Review Board Statement: Not applicable.

Informed Consent Statement: Not applicable.

Data Availability Statement: Data are available from the corresponding author, after reasonable request, for research purposes.

Conflicts of Interest: The authors declare no conflict of interest.

\section{Appendix A}

Table A1. Equations of the continuum model of the electrochemical processes in EDLCs.

Mass ion transport equations for all pore sizes $p\left(p=1\right.$ to $\left.\mathrm{N}_{\mathrm{p}}\right)$ and ions $i(i=+$ and -$)$ :

$$
\begin{gathered}
\frac{\partial \varepsilon_{p} \alpha_{i, p}}{\partial t}-\frac{\partial}{\partial x}\left(\frac{z_{i} F D_{i, p} \alpha_{i, p} F_{\text {decay }}}{R T} \frac{\partial \phi_{2}}{\partial x}\right)=\frac{\partial}{\partial x}\left(\varepsilon_{p} D_{i, p} F_{\text {decay }} \frac{\partial \alpha_{i, p}}{\partial x}\right)+ \\
I_{i, p-1 / p}-I_{i, p / p+1}
\end{gathered}
$$

Current flux of ion $i$ from pore $p-1$ to pore $p$ :

$$
I_{i, p-1 / p}=F_{\text {decay }} \frac{\varepsilon_{p-1} d_{p}^{2}}{\varepsilon_{p} d_{p-1}^{2}} \frac{z_{i} N_{A} V_{i} t_{i, p} i_{2}}{d x F}
$$

Decay factor if electrochemical energy, $E_{E C}$, is less than $\Delta E_{i, p} / R T$ :

$$
F_{\text {decay }}=e^{-\left(\frac{\Delta E_{i, p}}{R T+E_{E C}}\right)}
$$

\begin{tabular}{|c|c|}
\hline$\alpha_{i, p}=c_{i, p} N_{A} V_{i}$ & (A5) \\
\hline$\alpha_{+, p}(x)+\alpha_{-, p}(x)+\alpha_{s, p}(x)+\alpha_{v, p}(x)=1$ & (A6) \\
\hline $0 \leq \alpha_{+, p}(x) \leq 1, \quad 0 \leq \alpha_{-, p}(x) \leq 1, \quad 0 \leq \alpha_{+, p}(x)+\alpha_{-, p}(x) \leq 1$ & (A7) \\
\hline$i_{1}=-\sigma_{1} \frac{\partial \phi_{1}}{\partial x}$ & (A8) \\
\hline$i_{2, p}=-\sigma_{2, p} \frac{\partial \phi_{2}}{\partial x}-\frac{\sigma_{2, p} R T}{F}\left[t_{+, p} \frac{\partial \ln c_{+, p}}{\partial x}-t_{-, p} \frac{\partial \ln c_{-, p}}{\partial x}\right]$ & (A9) \\
\hline$i_{2}=\sum_{p=1}^{N_{p}} \varepsilon_{p} i_{2, p}$ & $(\mathrm{~A} 10)$ \\
\hline$\frac{\partial i_{1}}{\partial x}+\frac{\partial i_{2}}{\partial x}=0$ & $(\mathrm{~A} 11)$ \\
\hline Poisson equation: $\frac{\partial^{2} \varphi_{2}}{\partial x^{2}}=\frac{\sum_{i, p} z_{i} e \alpha_{i, p} /\left(N_{A} V_{i}\right)}{\varepsilon_{o} \varepsilon_{r}}$ & (A12) \\
\hline$\Delta \phi_{\text {stern }, i, p}=\frac{c_{i, p} z_{i} F v_{p} L_{s t e r n}}{A_{p} \varepsilon_{o} \varepsilon_{r}}$ & (A13) \\
\hline$D_{i, p}=\frac{\varepsilon_{p}^{1.5} \delta k_{B} T}{2 \pi \eta\left(d_{\text {solv.ion }} \text { or } d_{\text {ion }}\right)}$ & (A14) \\
\hline
\end{tabular}

Desolvation energy barrier for $d_{\text {ion }}<d_{p}<d_{\text {solvion+ }}$ (for larger pores: $\Delta n_{i}=0$ ):

$$
\Delta E_{i, p}=E_{i} \Delta n_{i} / n_{i}
$$


Table A1. Cont.

\begin{tabular}{|c|c|}
\hline$\delta_{i, p}=\left(1-\frac{d_{\text {solv.ion or } d_{i o n}}}{d_{p}}\right)^{4}$ & (A15) \\
\hline$\eta=\eta_{0} \frac{\left[1+0.5\left(\alpha_{+, p}+\alpha_{-, p}\right)\right]^{4.5}}{\left[1-\left(\alpha_{+, p}+\alpha_{-, p}\right)\right]^{2}}$ & (A16) \\
\hline$t_{i, p}=\frac{D_{i, p}}{D_{+, p}+D_{-, p}}$ & (A17) \\
\hline$\sigma_{2, p}=\frac{F^{2}\left[\left(z_{+}\right)^{2} D_{+, p} c_{+, p}+\left(z_{-}\right)^{2} D_{-, p} c_{-, p}\right)}{R T} \quad$ (Nernst-Einstein equation) & (A18) \\
\hline $\begin{array}{l}\text { Initial conditions, at } \mathrm{t}=0 \text {, before the first charge: } \\
c_{i, p}=k_{d} c_{0} \text { for } \mathrm{d}_{\mathrm{p}}>\mathrm{d}_{\mathrm{ion}, \mathrm{i}} \text { and } c_{i, p}=0 \text { for } \mathrm{d}_{\mathrm{p}}<\mathrm{d}_{\mathrm{ion}, \mathrm{i}} \\
\mathrm{i}_{1}=\mathrm{i}_{2}=0 . \phi_{1}=\phi_{2}=0\end{array}$ & (A19) \\
\hline $\begin{array}{c}\text { Boundary conditions: } \\
\text { At } x=x_{S} \text { (separator): } i_{1}=0 \quad \phi_{1}=0 \\
\text { At } x=0 \text { and } x=L \text { (current collector } / \text { cathode or anode): } \\
\left|\mathrm{i}_{1}\right|=\mathrm{i}_{\mathrm{O}} \text {, the current density in galvanostatic charge-discharge. }\end{array}$ & (A20) \\
\hline
\end{tabular}

Where subscript $\mathrm{p}$ : pore size $\mathrm{p}$, where $\mathrm{p}$ is integer from 1 to $\mathrm{N}_{\mathrm{p}}$; subscript $\mathrm{i}$ : + (positive ion) or - (negative ion).

Variables: $t$ : time; $x$ : the through-thickness direction in the cell from $x=0$ at the current collector of the cathode to $\mathrm{x}=\mathrm{L}$ at the current collector of the anode; $\alpha_{i, p}$ : volume fraction of $i$ ion in volume of pore $p ; c_{i, p}$ : molar concentration of $i$ ion in volume of pore $p ; i_{1}$ : electron current density in solid phase; $i_{2}$ : ion current density in the electrolyte phase; $\phi_{1}$ : potential of solid-phase; $\phi_{2}$ : potential of electrolyte phase in the non-Stern region.

Properties: $D_{i, p}$ : diffusion coefficient of ion $\mathrm{i}$ in pore $\mathrm{p} ; \delta_{\mathrm{i}, \mathrm{p}}$ : constrictivity of ion $i$ in pore $p ; t_{i, p}$ : transference number of ion $i$ in pore size $p ; \eta$ : viscosity of electrolyte: determined by equations given in Table 1.

Electrode: $\mathrm{v}_{\mathrm{p}}, \mathrm{A}_{\mathrm{p}}$ and $\varepsilon_{\mathrm{p}}$ : specific pore volume, specific wall surface area and pore fraction of pore p: specified from the experimental data of Sections 2 and 3.

Electrolyte: $V_{i}$ : volume of ion $i ; \Delta E_{i, p}$ : desolvation energy barrier in ion i in pore $p$; $\mathrm{E}_{\mathrm{i}}$ : solvation energy for first solvent shell around ion $\mathrm{i} ; \mathrm{n}_{\mathrm{i}}$ : coordination number of ion $\mathrm{i}$; $\Delta \mathrm{n}_{\mathrm{i}}$ : change of coordination number in desolvation of ion $\mathrm{i}$ in small micropore; $\eta_{\mathrm{o}}$ : viscosity of solvent; $\varepsilon_{\mathrm{r}}$ : relative permittivity of the electrolyte; $\mathrm{k}_{\mathrm{d}}$ : dissociation constant: input data with values listed in Table A1.

General parameters and variables: $z_{i}$ number of transferred electrons for ion $i ; N_{A}: A v-$ ocadro's number; F: Faraday constant; R: ideal gas constant; $\mathrm{k}_{\mathrm{B}}$ : Boltzmann constant, $\varepsilon_{\mathrm{o}}$ : vacuum permittivity; T: absolute temperature.

\section{References}

1. Simon, P.; Gogotsi, Y. Perspectives for electrochemical capacitors and related devices. Nat. Mater. 2020, 19, 1151-1163. [CrossRef] [PubMed]

2. Markoulidis, F.; Lei, C.; Lekakou, C. Investigations of activated carbon fabric-based supercapacitors with different interlayers via experiments and modelling of electrochemical processes of different timescales. Electrochim. Acta 2017, 249, 122-134. [CrossRef]

3. Pina, A.C.; Amaya, A.; Marcuzzo, J.S.; Rodrigues, A.C.; Baldan, M.R.; Tancredi, N.; Cuña, A. Supercapacitor Electrode Based on Activated Carbon Wool Felt. C J. Carbon Res. 2018, 4, 24. [CrossRef]

4. Lei, C.; Amini, N.; Markoulidis, F.; Wilson, P.; Tennison, S.; Lekakou, C. Activated carbon from phenolic resin with controlled mesoporosity for an electric double-layer capacitor (EDLC). J. Mater. Chem. A 2013, 1, 6037-6042. [CrossRef]

5. Lei, C.; Lekakou, C. Activated carbon-carbon nanotube nanocomposite coatings for supercapacitor applications. Surf. Coat. Technol. 2013, 232, 326-330. [CrossRef]

6. Reece, R.; Lekakou, C.; Smith, P.A. A High-Performance Structural Supercapacitor. ACS Appl. Mater. Interfaces 2020, 12, 2568325692. [CrossRef]

7. Vermisoglou, E.C.; Giannakopoulou, T.; Romanos, G.; Giannouri, M.; Boukos, N.; Lei, C.; Lekakou, C.; Trapalis, C. Effect of hydrothermal reaction time and alkaline conditions on the electrochemical properties of reduced graphene oxide. Appl. Surf. Sci. Part A 2015, 358, 100-109. [CrossRef]

8. Liu, G.; Yu, Z.; Neff, D.; Zhamu, A.; Jang, B.Z. Graphene-based supercapacitor with an ultrahigh energy density. Nano Lett. 2010, 10, 4863-4868. [CrossRef] 
9. Yang, H.; Kannappan, S.; Pandian, A.S.; Jang, J.-H.; Lee, Y.S.; Lu, W. Graphene supercapacitor with both high power and energy density. Nanotechnology 2017, 28, 445401. [CrossRef] [PubMed]

10. Vermisoglou, E.C.; Giannakopoulou, T.; Romanos, G.; Boukos, N.; Psycharis, V.; Lei, C.; Lekakou, C.; Petridis, D.; Trapalis, C. Graphene-based materials via benzidine-assisted exfoliation and reduction of graphite oxide and their electrochemical properties. Appl. Surf. Sci. 2017, 392, 244-255. [CrossRef]

11. Reece, R.; Lekakou, C.; Smith, P.A.; Grilli, R.; Trapalis, C. Sulphur-linked graphitic and graphene oxide platelet-based electrodes for electrochemical double layer capacitors. J. Alloy. Compd. 2019, 792, 582-593. [CrossRef]

12. Vermisoglou, E.C.; Giannakopoulou, T.; Romanos, G.E.; Boukos, N.; Giannouri, M.; Lei, C.; Lekakou, C.; Trapalis, C. Non-activated high surface area expanded graphite oxide for supercapacitors. Appl. Surf. Sci. Part A 2015, 358, 110-121. [CrossRef]

13. Lekakou, C.; Moudam, O.; Markoulidis, F.; Andrews, T.; Watts, J.F.; Reed, G.T. Carbon-based fibrous EDLC capacitors and supercapacitors. J. Nanotechnol. 2011. [CrossRef]

14. Izadi-Najafabadi, A.; Yamada, T.; Futaba, D.N.; Yudasaka, M.; Takagi, H.; Hatori, H.; Iijima, S.; Hata, K. High-power supercapacitor electrodes from single-walled carbon nanohorn/nanotube composite. ACS Nano 2011, 5, 811-819. [CrossRef] [PubMed]

15. Markoulidis, F.; Lei, C.; Lekakou, C. Fabrication of high-performance supercapacitors based on transversely oriented carbon nanotubes. Appl. Phys. A 2013, 111, 227-236. [CrossRef]

16. Markoulidis, F.; Lei, C.; Lekakou, C.; Duff, D.; Khalil, S.; Martorana, B.; Cannavaro, I. A method to increase the energy density of supercapacitor cells by the addition of multiwall carbon nanotubes into activated carbon electrodes. Carbon 2014, 68, 58-66. [CrossRef]

17. Markoulidis, F.; Todorova, N.; Grilli, R.; Lekakou, C.; Trapalis, C. Composite electrodes of activated carbon and multiwall carbon nanotubes decorated with silver nanoparticles for high power energy storage. J. Compos. Sci. 2019, 3, 97. [CrossRef]

18. Fields, R.; Lei, C.; Markoulidis, F.; Lekakou, C. The Composite supercapacitor. Energy Technol. 2016, 4, 517-525. [CrossRef]

19. Vermisoglou, E.C.; Giannouri, M.; Todorova, N.; Giannakopoulou, T.; Lekakou, C.; Trapalis, C. Recycling of typical supercapacitor materials. Waste Manag. Res. 2016, 34, 337-344.

20. Kampouris, E.M.; Papaspyrides, C.D.; Lekakou, C.N. A model recovery process for scrap polystyrene foam by means of solvent systems. Conserv. Recycl. 1987, 10, 315-319. [CrossRef]

21. Kampouris, E.M.; Papaspyrides, C.D.; Lekakou, C.N. A model process for the solvent recycling of polystyrene. Polym. Eng. Sci. 1988, 28, 534-537. [CrossRef]

22. Murugesh, A.K.; Uthayanan, A.; Lekakou, C. Electrophoresis and orientation of multiple wall carbon nanotubes in polymer solution. Appl. Phys. A 2010, 100, 135-144. [CrossRef]

23. Huang, J.; Sumpter, B.G.; Meunier, V. Theoretical model for nanoporous carbon supercapacitors. Angew. Chem. Int. Ed. 2008, 47, 520-524. [CrossRef] [PubMed]

24. Xiao, J.; Mei, D.; Li, X.; Xu, W.; Wang, D.; Graff, G.L.; Bennett, W.D.; Nie, Z.; Saraf, L.V.; Aksay, I.A.; et al. Hierarchically porous graphene as a lithium-air battery electrode. Nano Lett. 2011, 11, 5071-5078. [CrossRef] [PubMed]

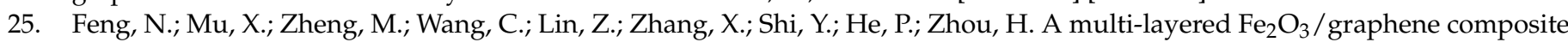
with mesopores as a catalyst for rechargeable aprotic lithium-oxygen batteries. Nanotechnology 2016, 27, 365402. [CrossRef]

26. Shui, J.; Lin, Y.; Connell, J.W.; Xu, J.; Fan, X.; Dai, L. Nitrogen-doped holey graphene for high-performance rechargeable Li-O 2 batteries. ACS Energy Lett. 2016, 1, 260-265. [CrossRef]

27. Xu, G.; Ding, B.; Nie, P.; Shen, L.; Dou, H.; Zhang, X. Hierarchically porous carbon encapsulating sulfur as a superior cathode material for high performance lithium-sulfur batteries. ACS Appl. Mater. Interfaces 2014, 6, 194-199. [CrossRef]

28. Robinson, J.; Xi, K.; Kumar, R.V.; Ferrari, A.C.; Au, H.; Titirici, M.M.; Puerto, A.P.; Kucernak, A.; Fitch, S.D.S.; Garcia-Araez, N. 2020 Roadmap on Lithium Sulfur Batteries. J. Phys. Energy 2021. accepted for publication.

29. Lei, C.; Fields, R.; Wilson, P.; Lekakou, C.; Amini, N.; Tennison, S.; Perry, J.; Gosso, M.; Martorana, B. Development and evaluation of a composite supercapacitor-based $12 \mathrm{~V}$ transient start-stop (TSS) power system for vehicles: Modelling, design and fabrication scaling up. Proc. Inst. Mech. Eng. Part A J. Power Energy 2020. [CrossRef]

30. Abouelamaiem, D.I.; He, G.; Neville, T.P.; Patel, D.; Ji, S.; Wang, R.; Parkin, I.P.; Jorge, A.B.; Titirici, M.-M.; Shearing, P.R.; et al Correlating electrochemical impedance with hierarchical structure for porous carbon-based supercapacitors using a truncated transmission line model. Electrochim. Acta 2018, 284, 597-608. [CrossRef]

31. Feng, G.; Huang, J.; Sumpter, B.G.; Meunier, V.; Qiao, R. Structure and dynamics of electrical double layers in organic electrolytes. Phys. Chem. Chem. Phys. 2010, 12, 5468-5479. [CrossRef] [PubMed]

32. Babar, S.; Lekakou, C. Molecular modeling of electrolyte and polysulfide ions for lithium-sulfur batteries. Ionics 2021, 27, 635-642. [CrossRef]

33. Lian, C.; Zhao, S.; Liu, H.; Wu, J. Time-dependent density functional theory for the charging kinetics of electric double layer containing room-temperature ionic liquids. J. Chem. Phys. 2016, 145, 204707. [CrossRef]

34. Wang, L.; Wang, J.; Zhang, Z.; Wang, L.; Wang, W.; Liu, J.; Hong, Z.; Cho, K.; Wang, W. Origin of theoretical pseudocapacitance of two-dimensional supercapacitor electrodes $\mathrm{Ti}_{3} \mathrm{C}_{2} \mathrm{~T}_{2}$ ( $\mathrm{T}=$ bare, $\left.\mathrm{O}, \mathrm{S}\right)$. J. Mater. Chem. A 2019, 7, 16231-16238. [CrossRef]

35. Drummond, R.; Howey, D.A.; Duncan, S.R. Low-order mathematical modelling of electric double layer supercapacitors using spectral methods. J. Power Sources 2015, 277, 317-328. [CrossRef] 
36. Di Lecce, D.; Marangon, V.; Du, W.; Brett, D.J.L.; Shearing, P.R.; Hassoun, J. The role of synthesis pathway on the microstructural characteristics of sulfur-carbon composites: X-ray imaging and electrochemistry in lithium battery. J. Power Sources 2020, 472, 228424. [CrossRef]

37. Bates, J. Modelling and Simulations of Energy Storage Devices. Ph.D. Thesis, University of Surrey, Guildford, UK, 2020.

38. Markoulidis, F.; Bates, J.; Lekakou, C.; Slade, R.; Laudone, G.M. Supercapacitors with lithium-ion electrolyte: An experimental study and design of the activated carbon electrodes via modelling and simulations. Carbon 2020, 164, 422-434. [CrossRef]

39. Bruggeman, D.A.G. Berechnung verschiedener physikalischer Konstanten von heterogenen Substanzen. I. Dielektrizitätskonstanten und Leitfähigkeiten der Mischkorper aus isotropen Substanzen. Ann. Phys. 1935, 416, 636-664. [CrossRef]

40. Beck, R.E.; Schultz, J.S. Hindered diffusion in microporous membranes with known pore geometry. Science 1970, 170, 1302-1305. [CrossRef]

41. Murch, G.E. The exact Nernst-Einstein equations and the interpretation of cross phenomenological coefficients in unary, binary, and ambipolar systems. Radiat. Eff. 1983, 73, 299-305. [CrossRef]

42. Amico, S.; Lekakou, C. Flow through a two-scale porosity, oriented fibre porous medium. Transp. Porous Media 2004, 54, 35-53. [CrossRef]

43. Lekakou, C.; Edwards, S.; Bell, G.; Amico, S.C. Computer modelling for the prediction of the in-plane permeability of non-crimp stitch bonded fabrics. Compos. A Appl. Sci. Manuf. 2006, 37, 820-825. [CrossRef]

44. Elsayed, Y.; Lekakou, C.; Tomlins, P. Modeling, simulations and optimization of smooth muscle cell tissue engineering for the production of vascular grafts. Biotechnol. Bioeng. 2019, 116, 1509-1522. [CrossRef] [PubMed]

45. Lekakou, C.N.; Richardson, S.M. Simulation of reacting flow during filling in reaction injection molding (RIM). Polym. Eng. Sci. 1986, 26, 1264-1275. [CrossRef]

46. Oldham, K.B. A Gouy-Chapman-Stern model of the double layer at a (metal)/(ionic liquid) interface. J. Electroanal. Chem. 2008, $613,131-138$.

47. Kannan, D.; Terala, P.; Moss, P.; Weatherspoon, M. Analysis of the separator thickness and porosity on the performance of lithium-ion batteries. Int. J. Electrochem. 2018, 2018, 1925708. [CrossRef]

48. Salifu, A.A.; Lekakou, C.; Labeed, F.H. Electrospun oriented gelatin-hydroxyapatite fiber scaffolds for bone tissue engineering. J. Biomed. Mater. Res. Part A 2017, 105, 1911-1926. [CrossRef]

49. Salifu, A.A.; Nury, B.D.; Lekakou, C. Electrospinning of nanocomposite fibrillar tubular and flat scaffolds with controlled fiber orientation. Ann. Biomed. Eng. 2011, 39, 2510. [CrossRef]

50. Zhao, C.; Zheng, W. A review for aqueous electrochemical supercapacitors. Front. Energy Res. 2015. [CrossRef]

51. Yu, L.; Chen, G.Z. Ionic liquid-based electrolytes for supercapacitor and supercapattery. Front. Chem. 2019. [CrossRef]

52. Heng, I.; Lai, C.W.; Juan, J.C. Organic electrolytes for supercapacitors. In Supercapacitor Technology; Materials Research Foundations: Millersville, PA, USA, 2019; Volume 61, pp. 1-10.

53. Chmiola, J.; Largeot, C.; Taberna, P.-L.; Simon, P.; Gogotsi, Y. Desolvation of ions in subnanometer pores and its effect on capacitance and double-layer theory. Angew. Chem. Int. Ed. 2008, 47, 3392-3395. [CrossRef] [PubMed]

54. Jagadale, A.; Zhou, X.; Xiong, R.; Dubal, D.P.; Xu, J.; Yang, S. Lithium ion capacitors (LICs): Development of the materials. Energy Storage Mater. 2019, 19, 314-329. [CrossRef]

55. Zhang, F.; Zhang, T.; Yang, X.; Zhang, L.; Leng, K.; Huang, Y.; Chen, Y. A high-performance supercapacitor-battery hybrid energy storage device based on graphene-enhanced electrode materials with ultrahigh energy density. Energy Environ. Sci. 2013, 6, 1623-1632. [CrossRef]

56. Choi, H.S.; Chong Park, R. Theoretical guidelines to designing high performance energy storage device based on hybridization of lithium-ion battery and supercapacitor. J. Power Sources 2014, 259, 1-14. [CrossRef]

57. Vlad, A.; Singh, N.; Rolland, J.; Melinte, S.; Ajayan, P.M.; Gohy, J.-F. Hybrid supercapacitor-battery materials for fast electrochemical charge storage. Sci. Rep. 2014, 4, 4315. [CrossRef] [PubMed]

58. Saito, M.; Kawaharasaki, S.; Ito, K.; Yamada, S.; Hayamizub, K.; Sekic, S. Strategies for fast ion transport in electrochemical capacitor electrolytes from diffusion coefficients, ionic conductivity, viscosity, density and interaction energies based on HSAB theory. RSC Adv. 2017, 7, 14528-14535. [CrossRef]

59. Perricone, E.; Chamas, M.; Cointeaux, L.; Leprêtre, J.-C.; Judeinstein, P.; Azais, P.; Béguin, F.; Alloin, F. Investigation of methoxypropionitrile as co-solvent for ethylene carbonate based electrolyte in supercapacitors. A safe and wide temperature range electrolyte. Electrochim. Acta 2013, 93, 1-7. [CrossRef]

60. Logan, E.R.; Tonita, E.M.; Gering, K.L.; Li, J.; Ma, X.; Beaulieu, L.Y.; Dahn, J.R. A study of the physical properties of li-ion battery electrolytes containing esters. J. Electrochem. Soc. 2018, 165, A21-A30. [CrossRef]

61. Afanas'ev, V.N.; Tyunina, E.Y.; Chekunova, M.D. The influence of temperature and concentration on viscous flow of solutions of Et4NBF4 in propylene carbonate. Russ. J. Phys. Chem. A 2009, 83, 2069-2073. [CrossRef]

62. Markoulidis, F. Materials and Processing Techniques for the Fabrication of Supercapacitors for Automotive Applications. Ph.D. Thesis, University of Surrey, Guildford, UK, 2014.

63. Hu, L.; Guo, D.; Feng, G.; Li, H.; Zhai, T. Asymmetric behavior of positive and negative electrodes in carbon/carbon supercapacitors and its underlying mechanism. J. Phys. Chem. C 2016, 120, 24675-24681. [CrossRef]

64. Gogotsi, Y.; Penner, R.M. Energy storage in nanomaterials-Capacitive, pseudocapacitive, or battery-like? ACS Nano 2018, 12, 2081-2083. [CrossRef] [PubMed] 
65. Forse, A.C.; Merlet, C.; Griffin, J.M.; Grey, C.P. New perspectives on the charging mechanisms of supercapacitors. J. Am. Chem. Soc. 2016, 138, 5731-5744. [CrossRef] [PubMed]

66. Deschamps, M.; Gilbert, E.; Azais, P.; Raymundo-Piñero, E.; Ramzi Ammar, M.; Simon, P.; Massiot, D.; Béguin, F. Exploring electrolyte organization in supercapacitor electrodes with solid-state NMR. Nat. Mater. 2013, 12, 351-358. [CrossRef] [PubMed]

67. Decaux, C.; Matei Ghimbeu, C.; Dahbi, M.; Anouti, M.; Lemordant, D.; Béguin, F.; Vix-Guterl, C.; Raymundo-Piñero, E. Influence of electrolyte ion-solvent interactions on the performances of supercapacitors porous carbon electrodes. J. Power Sources 2014, 263, 130-140. [CrossRef] 